\title{
Evaluation of antihypertensive adherence and its determinants at primary health care facilities in rural South Africa
}

\author{
Enos M Rampamba ${ }^{1,2}$, Johanna C Meyer ${ }^{1}$, Brian Godman³,4,5, Amanj Kurdi ${ }^{3}$, Elvera Helberg ${ }^{1}$ \\ 1School of Pharmacy, Sefako Makgatho Health Sciences University, Ga-Rankuwa, Pretoria, 0208, \\ South Africa. Email: mrampamba@gmail.com; hannelie.meyer@smu.ac.za; elvera@mweb.co.za \\ 2Department of Health, Tshilidzini Hospital, Limpopo Province, South Africa. Email: \\ mrampamba@gmail.com \\ 3Strathclyde Institute of Pharmacy and Biomedical Sciences, University of Strathclyde, Glasgow, \\ United Kingdom. Email: Brian.godman@strath.ac.uk; amanj.baker@strath.ac.uk \\ 4Department of Laboratory Medicine, Division of Clinical Pharmacology, Karolinska Institutet, \\ Karolinska University Hospital Huddinge, Stockholm, Sweden. Email: Brian.Godman@ki.se \\ 5Health Economics Centre, Liverpool University Management School, Liverpool, UK. Email: \\ Brian.Godman@liverpool.ac.uk
}

Author for correspondence: Brian Godman, Division of Clinical Pharmacology, Karolinska Institute, Karolinska University Hospital Huddinge, SE-141 86, Stockholm, Sweden. Email:

Brian.Godman@ki.se; Telephone: +46 8 58581068. Fax: +46 859581070 and Strathclyde Institute of Pharmacy and Biomedical Sciences, University of Strathclyde, Glasgow G4 ORE, United Kingdom. Email: brian.godman@strath.ac.uk .

(Accepted for publication in Journal Comparative Effectiveness Research - Please keep Confidential)

\begin{abstract}
Introduction and aim: To evaluate adherence to antihypertensive treatment in rural South Africa and identify potential determinants given concerns with adherence and its impact in this priority disease area. Method: Face-to-face interviews with hypertensive patients and rating their adherence to treatment using defined categorised responses. Associations between adherence and patient characteristics assessed and sensitivity analyses performed. Results: $54.6 \%$ of patients were adherent to treatment. Controlled blood pressure (OR $=:=2.1 ; 95 \% \mathrm{Cl}[: 1.1,-3.8] ; p=0.019)$, comorbidity (OR = :=2.0; 95\% Cl [: 1.1, -3.6]; $p=0.032)$ and smoking (OR = :=0.3; 95\% Cl [:0.1, -0.8$]$; $p=0.018$ ) were associated with adherence. Conclusion: Adherence and BP control were suboptimal, only smoking was an independent risk factor for adherence. Adherent patients were twice as likely to have controlled BP, although results were sensitive to the definition of adherence. Initiatives are in place to improve adherence, which will be monitored.
\end{abstract}

\section{Introduction}

Hypertension is a major public health concern worldwide [1-5], with an estimated 17.7 million people worldwide in 2008 dying annually from cardiovascular disease (CVD), accounting for more than a third of all deaths due to non-communicable diseases (NCDs) [2, 3]. Of these 17.7 million deaths, hypertension currently accounts for 9.4 million $(50 \%)$ deaths [1-2]. Patients living in low and middle income countries (LMICs) account for the majority of patients with hypertension worldwide as well as deaths due to uncontrolled blood pressure [1, 2, 4-7]. The World Health Organization (WHO) estimates that up to three quarters of all deaths in Africa could soon be due to hypertension if not adequately addressed [2,3]. The greatest prevalence worldwide for hypertension is in the African Region, where up to $46 \%$ of adults aged 25 or over in 2008 had hypertension [2], with up to three quarters or more of hypertensive patients currently failing to achieve target blood pressure (BP) goals [7-12]. It is perceived that a lack of adherence to medication is the major causative factor for uncontrolled hypertension [1, 4, 6-8, 11-16]. Non-adherence to medicines affects up to $30-50 \%$ of patients or more with chronic conditions including hypertension $[8,17,18]$, with poor adherence levels seen even in the first year of treatment $[12,19,20]$. The consequences of non-adherence to antihypertensive medication are not only poorer health outcomes, including higher cardiovascular mortality, but also increased health care costs and poorer economy to the country [1, 17,18, 20-22]. As a result, the $\mathrm{WHO}$ and others recognise the burden of medication non-adherence as an important public health concern, necessitating urgent action $[1,2,14,20,23]$. 
In South Africa, NCDs are a common reason for patients to visit primary health care (PHC) facilities, with over $50 \%$ or more of adults in South Africa potentially having hypertension [24-26]. Currently over $80 \%$ of the population in South Africa are treated in the public health sector, where there is a high burden of NCDs [24, 26]. Rates of hypertension are rising in South Africa, with hypertension now accounting for the greatest reason why patients with NCDs visit PHC facilities, enhanced by high levels of overweight and obesity among the population [26, 27]. In addition, hypertension was the sixth leading cause of death in South Africa in 2016 accounting for $4.4 \%$ of deaths [28]. Currently there are limited attempts to address this, although the situation is changing with ongoing initiatives to improve the management of patients with chronic diseases in South Africa [25, 26, 29].

Factors affecting adherence are complex [1, 6], and can include patients' beliefs and perceptions about the disease and treatment, medication side-effects, treatment regimens, treatment support including family members, unintentional behaviour such as patients forgetting to take their medication or intentional behaviour as in the case of certain beliefs and perceptions $[1,6,11,12,14,30]$. Other factors affecting adherence include unrealistic expectations of treatment such as a cure for their hypertension, depression from being newly diagnosed or knowing that hypertension is not curable, as well as the use of herbal preparations [9, 10,12, 31]. Unavailability of antihypertensive medicines at PHC facilities, a low level of formal education, and other factors such as the distance to treatment facilities, medication costs, and the availability of professional guidance, are also associated with nonadherence to treatment $[7,9,12,16,30,32]$.

The cornerstone of BP control in hypertensive patients is adherence to both pharmacological and non-pharmacological management of hypertension [9, 10, 12, 31, 33-35]. Non-pharmacological treatments include reducing salt intake, improving diets and increasing exercise levels [12, 13, 34]. Adherence to chronic medication results in better healthcare outcomes for patients, in this case better BP control $[12,14,33,36]$.

As a result, health care providers should have the necessary knowledge and skills to assess adherence, and to assist patients to improve their adherence to antihypertensive treatment where this is a concern [12, 24, 37, 38]. Successful outcomes in the management of hypertension require information on patient medication-taking behaviour, factors hindering adherence where these are a concern, as well as knowledge about patients' beliefs and perceptions concerning their antihypertensive medication [12, 21, 35].

In view of this, the aim of this study was to determine the level of adherence to antihypertensive medication in practice as well as explore a possible relationship between adherence and factors affecting adherence levels in South Africa. This is increasingly important in South Africa with the implementation of the Central Chronic Medicines Dispensing and Distribution (CCMDD) programme [26]. The CCMDD programme aims to improve access to chronic medicines as a two-month supply of patients' medicines are delivered to the nearest preferred pick-up point along with physician consultations every six months [39, 40]. In addition, the first Remote Pharmacy Dispensing Unit (RPDU) was recently launched by the Gauteng Health Department, in cooperation with a private provider, for service delivery closer to a patient's workplace or home to enhance medicine access. Under this scheme, there is the potential for internet interaction between patients and telepharmacists. In addition, the date for the next collection is shown on the receipt the patient receives when collecting their medication with reminders sent by SMS, with late collections highlighted to aid adherence in patients with chronic diseases $[41,42]$. However, both schemes limit contact between the patient and health care professionals although better with the RPDU scheme. Furthermore, there are also concerns with the current level of information seeking behaviour among South Africans [43]. Consequently, the findings of this study can be used as a baseline of patients' adherence to chronic medicines prior to enrolment on the CCMDD programme to help plan future interventions to further improve chronic disease management in South Africa.

\section{Method}

\section{Study setting}

The study was conducted at $50 \mathrm{PHC}$ facilities, conveniently selected from the $120 \mathrm{PHC}$ facilities in the Vhembe District. These facilities were accessible to pharmacists visiting the facilities as part of their practice, and who also served as data collectors. The Vhembe District is a rural district and the most northern district of Limpopo Province, in South Africa. Limpopo Province is also the most northern 
province in the country. Consequently, in view of more limited access to healthcare facilities in rural areas of South Africa versus urban areas and less monitoring of patients, it is vital that adherence rates are kept high in these areas through pertinent initiatives. There will now be even less contact between health care professionals and hypertensive patients with the introduction of CCMDD [25, 26], although potentially better with remote personnel under the RPDU scheme $[41,42]$. Consequently, our desire to initiate this research in this region. Health care services in the Vhembe District are delivered by district hospitals, PHC facilities (PHC clinics and community health centres) and mobile services.

\section{Study design}

A cross-sectional descriptive design was used as part of an operational study to measure adherence to antihypertensive treatment amongst chronic hypertensive patients collecting their medication from PHC facilities. Adherence data were collected at one time point between June and August 2015. Considering that both direct and indirect methods of measuring adherence have their own advantages and disadvantages and currently that there is no gold standard method, adherence was assessed through patient self-reporting using structured face-to-face interviews. Patient self-reporting is convenient to use in daily practice both in cost terms and practicability [44]. Evidence also showed that cognitive testing of self-reported adherence items revealed that participants felt more comfortable and confident with words compared to numbers, and the cognitive process of estimation matched better with the words than numbers [45]. Patients' blood pressure (BP), taken by clinic staff on the day of the interview, was obtained from their file, while other patient characteristics were collected during the interview.

\section{Study sample and recruitment}

Due to the operational nature of the study, convenient and consecutive sampling was used by pharmacists visiting PHC facilities to recruit $1-15$ hypertensive patients, $\geq 18$ years, and on chronic antihypertensive treatment, at each of the $50 \mathrm{PHC}$ facilities on the day of the visit. The 50 clinics included facilities from all different geographical parts in all the municipalities in the Vhembe District. The study population was randomly selected from hypertensive patients who had been on treatment for more than 6 months and were consulting on the day of data collection. Data collectors would identify any hypertensive patients sitting in the queue for consultation by checking their files and subsequently recruit them to participate in the study. Any hypertensive patients who had their vital signs taken on that day, and who met the inclusion criteria, were recruited. A total of 253 hypertensive patients were subsequently enrolled. Two patients lacked some of their adherence data and were subsequently excluded from the analysis, leaving 251 patients for complete analysis. Pregnant patients and patients who were severely ill on the day of data collection were excluded from the sample as this is a common practice in such research [46]. In addition, excluded for logistical reasons such as the fact that they might not be in a position to sit for a period of time to complete the interview, in addition to their consultation time. Patients were recruited after the collection of their medicines and the recording of their vital signs. Resting BP, taken on the day of the interview by nurses trained on the procedure, were recorded from patients' files onto the questionnaire. The resting BP was measured on either arm of the patient using a digital automatic BP monitor or a sphygmomanometer, depending on their availability at the PHC facility. Patients' height and weight were also measured on the day of the interview using a mobile stadiometer and a column standing scale. On completion of the interview, the next available patient meeting the inclusion criteria was recruited.

\section{Data collection procedures and data collection instrument}

The structured questionnaire was administered by trained data collectors, who were all pharmacists. Adherence was assessed using a self-reported rating scale with six pre-defined categorised responses, i.e. excellent, very good, good, fair, poor and very poor, previously used in adherence studies $[1,45,47]$. The scale measured the ability of patients in taking their medication in the last 30 days prior to the interview, according to these six categories. Published evidence suggests that patients may provide better estimates of adherence on a 30-day recall compared to a three-day or seven-day recall period $[45,48]$.

The questionnaire also collected information on factors that previously have been shown to be associated with adherence. These included gender, education, level of BP control, comorbidities, family history, knowledge of hypertension management, physical activity and smoking, in line with previous studies [1, 12, 14, 36, 49]. With the exception of vital signs, such as BP and body mass index (BMI), all the information was received from self-reporting. The questionnaire was tested in a 
pilot study amongst 20 hypertensive patients on treatment prior to the actual study to ascertain the suitability and feasibility for the study population. Amendments were made prior to commencement of data collection to enhance the robustness of the final questionnaire. Responses to the questions in the interview and the BP reading taken on the day of the interview were recorded on the questionnaire.

\section{Data analysis}

Data were captured on Microsoft Excel ${ }^{\mathrm{TM}}$ spread sheets and cross-checked for accuracy and correctness. Discrepancies were rectified prior to commencement of data analysis. Data were analysed using $\mathrm{SAS}^{\circledR}$ version 9.4 .

Descriptive statistics were used to summarise the study variables using frequencies and proportions for categorical variables and mean with standard deviation (SD) for continuous variables. For the main analysis, adherent patients were defined as those who rated their adherence over the past 30 days as excellent, whilst non-adherence refers to those who rated their adherence as either very good, good, fair, poor or very poor. This categorisation was used based on the fact that excellence was translated to $\geq 80 \%$ adherence. This is because at least $80 \%$ and above of antihypertensive medication adherence is significantly associated with controlled BP [1, 12, 30]. Another basis for these categorisation was the assumption that patients exaggerate their responses based on their perceptions about the interview [21], and as such the authors assumed that patients who rated themselves 'excellent', either exaggerating or not, were likely to be adherent to $\geq 80 \%$ of their doses.

A univariate association between adherence (dependant variable) and patient characteristics (sociodemographic and hypertension-related factors) was tested using the Chi-square test. For statistical significance, a two-sided $p$-value $\leq 0.05$ was accepted. Cramér's $V$ statistic was used to test the practical significance of these associations, with a value of 0.1 indicating a small effect, 0.3 a medium effect and 0.5 a large effect.

Adjusted associations between adherence and study covariates was assessed using a multivariate logistic regression with 'adherent' defined as an 'excellent' rating. Odds ratios (OR) and 95\% confidence intervals $(95 \% \mathrm{Cl})$ were calculated. In order to assess whether using an 'excellent' rating to classify patients as adherent had any impact on the study results, we conducted sensitivity analyses whereby we used another two different rating definitions for classifying patients as adherent; firstly patients who rated their adherence as either 'excellent', or 'very good' were classified as adherent; and secondly patients who rated their adherence cover as either 'excellent', 'very good' or 'good' were classified as adherent.

\section{Ethical considerations}

The Medunsa Research Ethics Committee of the University of Limpopo (currently Sefako Makgatho Health Sciences University) provided ethical clearance for the study (Clearance number:

MREC/H/27/2014:PG). Permission to conduct the study was obtained from the Limpopo Department of Health and Vhembe District Executive Manager. All patients provided written informed consent for participation. A unique study identification number was allocated to each patient and no personal details were recorded to maintain confidentiality.

\section{Results}

\section{Blood pressure and self-reported adherence}

The study patients included 251 black hypertensive patients, the vast majority $(82.4 \% ; 206, n=251)$ being female with a mean age of 63 years (SD: 11.4). A third of patients were in the age group of 6170 years and $61.0 \%$ were married. More than half of the patients did not have any education, and only a small minority had a tertiary education. Nearly two thirds of patients were on antihypertensive treatment for more than five years. All patients were treated with one or more antihypertensive drugs listed in the SA PHC Essential Medicines List and Standard Treatment Guidelines [26, 33]. These included hydrochlorothiazide $12.5 \mathrm{mg}$ or $25 \mathrm{mg}$ in the morning, enalapril $10 \mathrm{mg}$ once or twice daily, amlodipine $5 \mathrm{mg}$ daily and atenolol $50 \mathrm{mg}$ daily. However, only $46.3 \%$ of patients had controlled BP (SBP: $<140 \mathrm{mmHg}$; DBP: $<90 \mathrm{mmHg}$ ), while $7.9 \%$ had severe hypertension (SBP: $\geq 180 \mathrm{mmHg}$; DBP: $\geq 110 \mathrm{mmHg}$ ) [40] on the day of the interview (Figure 1). Patients' blood pressure on the day of the interview was used to determine whether their BP is controlled or not based on the fact that all the patients were on treatment for more than six months and that a once-off measurement of BP has 
been used previously among hypertensive patients on treatment to determine if they are controlled or not [50].

Figure 1: Patients categorized according to blood pressure control $(n=240)$

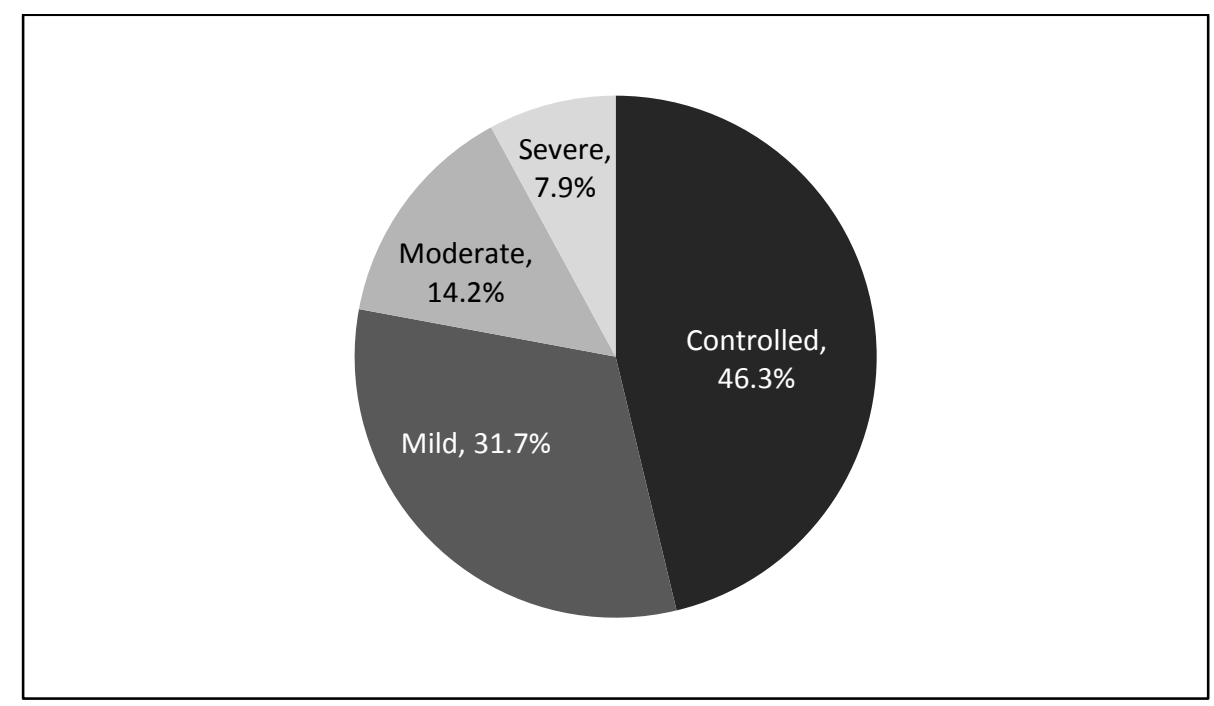

Figure 2 shows the proportion of patients per adherence rating. Only half of the patients $(54.6 \% ; 137$, $\mathrm{n}=251$ ) rated their adherence in the last 30 days as 'excellent' and were categorised as adherent.

Figure 2: Proportion of patients per adherence rating during the past 30 days $(n=251)$

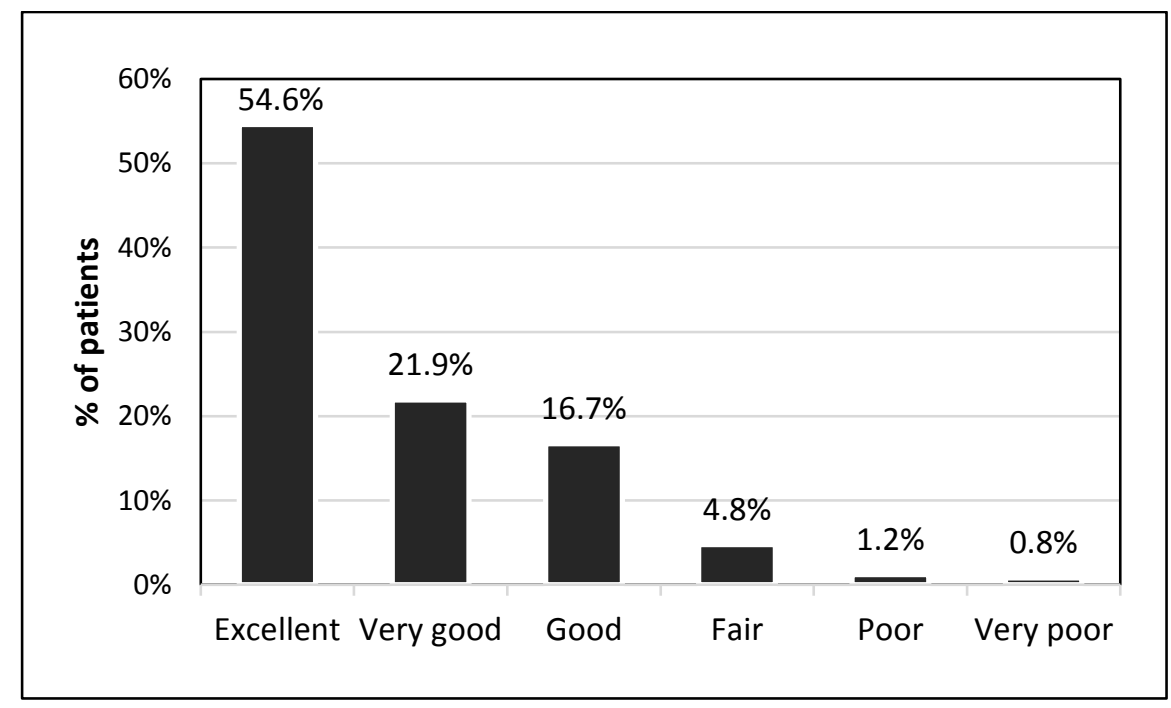

\section{Patient characteristics and adherence to anti-hypertensive medication}

Table 1 shows that with a univariate analysis there were only two significant associations between adherence to antihypertensive medication and patients' basic demographics. The proportion of adherent patients among the educated group (62.2\% of 111 patients) was significantly higher $(p=$ 0.036 ) than those among the non-educated group ( $48.9 \%$ of 139 patients). Secondly, only $31.0 \%$ of the 29 smokers were adherent, compared to $57.7 \%$ of the 222 non-smokers $(p=0.006)$. With borderline significance $(p=0.054), 61.9 \%$ of 118 patients with co-morbidities reported adherence compared to $49.6 \%$ of the 127 patients without any co-morbidity. There was no clear association between the period on antihypertensive medication or family history of hypertension and adherence rates. For all variables, the effect size of the association with adherence was small and not practically significant, as indicated by the Cramér's $V$ statistic. 
Table 1: Patient characteristics by adherence category

\begin{tabular}{|c|c|c|c|c|c|c|}
\hline \multirow{2}{*}{\multicolumn{2}{|c|}{ Patients characteristics }} & \multicolumn{3}{|c|}{ Patients; n (\%) } & \multirow{4}{*}{$\frac{p^{*}}{0.896}$} & \multirow{3}{*}{$\begin{array}{c}\begin{array}{c}\text { Cramer's } \\
\text { V }\end{array} \\
-0.008\end{array}$} \\
\hline & & \multirow{2}{*}{$\begin{array}{c}\text { Overall } \\
201(82.4)\end{array}$} & \multirow{2}{*}{$\begin{array}{l}\text { Adherent } \\
110(54.7)\end{array}$} & \multirow{2}{*}{$\begin{array}{c}\text { Non-adherent } \\
91(45.3)\end{array}$} & & \\
\hline Gender & Female & & & & & \\
\hline$(\mathrm{n}=244)$ & Male & $43(17.6)$ & $24(55.8)$ & $19(44.2)$ & & \\
\hline \multirow{2}{*}{$\begin{array}{l}\text { Educational level } \\
(\mathrm{n}=250)\end{array}$} & Educated & $111(44.4)$ & $69(62.2)$ & $42(37.8)$ & \multirow{2}{*}{0.036} & \multirow{2}{*}{0.132} \\
\hline & No education & $139(55.6)$ & $68(48.9)$ & $71(51.1)$ & & \\
\hline \multirow{2}{*}{$\begin{array}{l}\text { Marital status } \\
(\mathrm{n}=244)\end{array}$} & Married & $153(62.7)$ & $78(51.0)$ & $75(49.0)$ & \multirow[t]{2}{*}{0.350} & \multirow[t]{2}{*}{-0.059} \\
\hline & Single & $91(37.3)$ & $52(57.1)$ & $39(42.9)$ & & \\
\hline \multirow{2}{*}{$\begin{array}{l}\text { Blood pressure } \\
(\mathrm{n}=239)\end{array}$} & Controlled & $112(46.9)$ & $67(59.8)$ & $45(40.2)$ & \multirow[t]{2}{*}{0.143} & \multirow[t]{2}{*}{-0.094} \\
\hline & Uncontrolled & $127(53.1)$ & $64(50.4)$ & $63(49.6)$ & & \\
\hline \multirow{3}{*}{$\begin{array}{l}\text { Period on } \\
\text { antihypertensive } \\
\text { treatment }(n=249)\end{array}$} & $<1$ year & $16(6.4)$ & $7(43.8)$ & $9(56.2)$ & 0.368 & 0.056 \\
\hline & $1-5$ years & $77(30.7)$ & $40(51.9)$ & $37(48.1)$ & 0.577 & 0.035 \\
\hline & $>5$ years & $156(62.2)$ & $89(57.1)$ & $67(42.9)$ & 0.314 & -0.063 \\
\hline \multirow{3}{*}{$\begin{array}{l}\text { Family history of } \\
\text { hypertension } \\
(\mathrm{n}=248)\end{array}$} & Known family history & $121(48.8)$ & $71(58.7)$ & $50(41.3)$ & \multirow[t]{3}{*}{0.224} & \multirow[t]{3}{*}{0.109} \\
\hline & Do not know & $36(14.5)$ & $21(58.3)$ & $15(41.7)$ & & \\
\hline & No family history & $91(36.7)$ & $43(47.3)$ & $48(52.8)$ & & \\
\hline \multirow{2}{*}{$\begin{array}{l}\text { Physical activity } \\
(\mathrm{n}=248)\end{array}$} & Physical exercise & $149(60.1)$ & $84(56.4)$ & $65(43.6)$ & \multirow[t]{2}{*}{0.550} & \multirow[t]{2}{*}{-0.037} \\
\hline & No physical exercise & 99 (39.9) & $52(52.5)$ & $47(47.5)$ & & \\
\hline \multirow{2}{*}{$\begin{array}{l}\text { Co-morbidities } \\
(\mathrm{n}=245)\end{array}$} & Co-morbidity & $118(48.2)$ & $73(61.9)$ & $45(38.1)$ & \multirow[t]{2}{*}{0.054} & \multirow[t]{2}{*}{-0.123} \\
\hline & No co-morbidity & $127(51.8)$ & $63(49.6)$ & $64(50.4)$ & & \\
\hline \multirow{2}{*}{$\begin{array}{l}\text { Smoking } \\
(\mathrm{n}=251)\end{array}$} & Smokers & $29(11.5)$ & $9(31.0)$ & $20(69.0)$ & \multirow[t]{2}{*}{0.006} & \multirow[t]{2}{*}{0.170} \\
\hline & Non-smokers & $222(88.5)$ & $128(57.7)$ & $94(42.3)$ & & \\
\hline
\end{tabular}

Note: Data for some patients were not available, hence, difference in overall sample size; ${ }^{*}$ Chi Square test

\section{Independent factors associated with adherence}

Only patients who had complete information on all the study covariates were included in a multivariate logistic regression analysis $(n=206)$. With the multivariate logistic regression analysis, when adherence was defined as an 'excellent' rating, significant factors that were independently associated with adherence to hypertensive medication were as follows: $\mathrm{BP}$ controlled $(\mathrm{OR}=2.1 ; 95 \% \mathrm{Cl}[1.1,8]$; $\mathrm{p}=0.019)$, comorbidity $(\mathrm{OR}=2.0 ; 95 \% \mathrm{Cl}[1.1,3.6] ; \mathrm{p}=0.032)$ and smoking $(\mathrm{OR}=0.3 ; 95 \% \mathrm{Cl}[0.1$, 0.8 ; $p=0.018$ ) (Table 2). These results are however sensitive to the definition of adherence. When the definition of adherence was extended to a rating of 'excellent' and 'very good', only BP controlled $(\mathrm{OR}=2.6 ; p=0.013)$ was significantly associated with higher adherence, whereas when a wider definition of adherence is used (i.e. 'excellent', 'very good' and 'good'), none of the factors were significantly associated with adherence.

Table 2: Independent factors associated with adherence to antihypertensive treatment $(n=206)$

\begin{tabular}{|l|c|c|c|}
\hline \multirow{2}{*}{ Patient characteristics } & \multicolumn{3}{|c|}{ Adherent ('excellent' rating) } \\
\cline { 2 - 4 } & Odds Ratio & $\mathbf{9 5 \%}$ CI & $\boldsymbol{p}^{*}$ \\
\hline Age & 1.0 & $1.0,1.0$ & 0.422 \\
\hline Male & 1.3 & $0.6,2.9$ & 0.574 \\
\hline Educated & 1.4 & $0.7,2.7$ & 0.385 \\
\hline Single & 1.1 & $0.6,2.1$ & 0.775 \\
\hline Blood pressure controlled & 2.1 & $1.1,3.8$ & 0.019 \\
\hline$>5$ years on treatment & 0.7 & $0.3,1.3$ & 0.253 \\
\hline Family history of hypertension & 0.9 & $0.4,1.7$ & 0.688 \\
\hline No physical activity & 1.2 & $0.6,2.2$ & 0.573 \\
\hline Co-morbidity & 2.0 & $1.1,3.6$ & 0.032 \\
\hline Smoking & 0.3 & $0.1,0.8$ & 0.018 \\
\hline
\end{tabular}

*Multivariate logistic regression

\section{Discussion}

The reported proportion of patients rating themselves as adherent (54.6\%) to antihypertensive medication in this study is similar to adherence rates reported at an outreach clinic in Nigeria $(51 \%)$, PHC clinics in Hong Kong (55.1\%) and a cardiovascular clinic in Tanzania (54\%) [12, 51, 52]. Slightly 
lower rates were reported in a Namibian study conducted in public sector PHC facilities, with less than half $(42.5 \%)$ of patients reporting acceptable adherence levels of $\geq 80 \%$ [30]. On the other hand, this study finding is different from a previous study conducted at a clinic in a rural village of Limpopo Province, South Africa, where $80 \%$ of patients reported adherence to antihypertensive medication [53]. This may be because of the strict definition we used for adherence in this study, i.e. 'excellent' as opposed to 'excellent', 'very good' and 'good'.

There was no statistical significant relationship between gender and medication adherence in our study, which is different from the study conducted in China where higher adherence was found amongst males [54] as well as the meta-analysis of Nielsen et al where higher adherence rates were seen in women [1]. We are not sure of the reasons for this, but we will be investigating this further in future research. There was also no significant relationship between age and adherence, which is different to other studies [1], and again we will be investigating this further in future research projects. However, this study reaffirmed the findings of previous studies [1], which found that the level of education can have a direct influence on the extent of medication adherence. This is because a lack of formal education prevents patients from accessing and reading medicine information, as well as understanding labelled medication instructions $[7,9,10,12,43,55]$.

There was no significant relationship between marital status and adherence, which is similar to a study conducted in Ghana and Nigeria [9]. The lack of any statistical significant association between claimed adherence and the period on treatment, reminder (help) to take their medication by either a family member or friend, as well as perceptions and beliefs about hypertension and its treatment, are different from studies previously conducted in South Africa [37,56] as well as wider [1]. The results also differ from studies conducted in Namibia and Nigeria, which reported that patients with good family support or social support from friends had better adherence than those without $[30,57,58]$. We will again be researching this further in the future as this again has implications for additional programmes to improve adherence rates among hypertensive patients in South Africa combined with the recent CCMDD programme and the recently launched PRDU programme.

Previous evidence showed that there is a relationship between medication adherence and patients' perceptions and beliefs of hypertension and its treatment [1,12]; however, this was also not seen in our study. Perceptions that hypertension is not a chronic disease, is curable, and that it is curable through the use of herbal preparations, can also lead to non-adherence [9, 11], which must be factored into any future educational initiatives surrounding the treatment of patients with hypertension.

Unlike other studies, we did not find a statistical significant relationship between the level of adherence and most of the studied variables. This lack of statistical significant relationship may be due to the fact that the patients in this study had similar demographic characteristics and experiences [59]. In addition, different methodologies have been used for measuring adherence rates [1, 12, 30] as well as concerns with the subjective measures of adherence with increased probability that patients provide answers that conform to their perceived expectations and those of the interviewer $[18,59]$. Differences in study results may also be due to our sample size and the number of variables measured.

A positive finding of this study was that there was no correlation between the period on antihypertensive medication and medication adherence. This adds to what is already known, i.e. that a long period on treatment does not necessarily translate into better adherence to medication or control of BP $[30,60$. The high adherence rate to recommended medicines in the SA Standard Treatment Guidelines is also very encouraging given variable adherence to guidelines that has been seen in practice [61 - 64]. This will be explored further in future studies to provide guidance to others.

As seen, the multivariate logistic analysis results were very sensitive to the definition of adherence. For instance, when a wider definition of adherence ('excellent', 'very good' and 'good') was used, none of the factors were associated with adherence. When the definition of adherence was narrowed to 'excellent' and 'very good', only BP control was significantly associated with higher adherence. Whereas when adherence was limited to 'excellent', BP control, comorbidities and smoking were significantly associated with adherence. Only smoking and having a co-morbidity were independent risk factors for adherence to anti-hypertensive medications, with patients who smoke highly unlikely to adhere to treatment whereas patients with co-morbidities have a greater chance of adhering to treatment. Compared with non-adherent patients, adherent patients were twice as likely to have their 
BP controlled, which is congruent with other studies that have demonstrated a higher proportion of uncontrolled BP in non-adherent patients and that adherent patients are up to five times more likely to have their blood pressure controlled $[8,49]$.

Further research is needed to identify additional contributing factors to non-adherence in South Africa to inform relevant strategies to improve adherence to treatment amongst hypertensive patients, especially with the advent of the CCMDD and PRDU programmes. It is recommended that health education should be provided to both educated and non-educated patients of all genders concerning the understanding of antihypertensive treatment, possible side-effects of medication, and the hypertension process, to improve medication adherence in the future, building on current programmes. We also believe patient education should be provided using different ways that may include counselling on medication as well as possibly written information depending on education levels that describes hypertension and its treatment, both pharmacologically and nonpharmacologically, to promote good adherence.

Based on their extensive training on medicines, pharmacists are in an ideal position to provide continuous counselling and education to patients $[40,47,64,65]$. Patient counselling and education by pharmacists would not only improve adherence to medication, but also close this identified gap in the management of hypertension through providing continuous counselling and education as required by South African legislation [26, 34]. These are considerations for the future and will be part of future research programmes.

\section{Limitations}

We acknowledge that this study had a number of limitations. Firstly, it was only conducted in one district of the Limpopo Province in South Africa with a rural rather than urban population. Secondly, the unavailability of data in the files of some of the study patients compromised the sample size for certain variables. Thirdly, there were logistical issues during data collection such as unavailability of data collectors and patient availability. However, we believe our study does have interesting results to guide future activities to enhance the management of hypertension in South Africa, given current high prevalence rates and the priority to reduce morbidity, mortality and costs in this group. In addition, provide guidance alongside the recent CCMDD and PRDU programmes, especially in rural populations.

\section{Conclusion}

Both adherence and BP control were sub-optimal in this study population. Only half of the patients $(54.6 \%)$ considered themselves as adherent to antihypertensive medication and less than half of the patients' BP was controlled (46.3\%). Only smoking was an independent risk factor for adherence to anti-hypertensive medication. Compared with non-adherent patients, adherent patients were twice as likely to have controlled BP and a co-morbidity. The results were however very sensitive to the definition of adherence. In resource-limited settings where self-reported adherence is the most feasible method for measuring adherence, such as in South Africa, attention should focus on how to define adherence in the future.

Improving adherence in this hypertensive patient population can improve BP control, which is important with the instigation of initiatives to improve medicine availability in patients with chronic diseases in South Africa. Initiatives can include education of patients. However, further research is needed to identify additional factors contributing to non-adherence, and to inform relevant future strategies to improve adherence. Studies are underway to address this to provide direction to the authorities in South Africa and wider as African countries seek to introduce universal health care. With the current implementation of the CCMDD and PRDU programmes in South Africa, low medication adherence is a concern that needs to be further addressed as this can prevent the achievement of a long and healthy life for all.

\section{Acknowledgements}

The authors thank all the participants for their time and willingness to participate in this study. Special appreciation goes to the PHC facilities' personnel for their support. The following pharmacists who assisted with data collections are all appreciated for their commitment: Ms RG Ndleve, Ms LP Mathabi, Mr NJ Tsita, Mr VA Mathonsi, Ms N Netshiavha, Ms MC Masingi, Mr TC Raphiri, Ms I 
Tauatswala, Ms P Maluleke, Ms P Chauke and Ms T Raulisa who assisted with the data collection. Prof HS Schoeman is acknowledged for his assistance with the statistical analysis of the data.

\section{Competing interests}

The authors declare no competing interest. There was no financial support for this paper.

\section{Authors' contributions}

EMR, JCM and EH developed the concept and designed the study. EMR and BG conducted the literature review. EMR collected the data, which was supervised by JCM and EH. EMR, JCM and AK analysed the data and EMR and BBG drafted the first draft of the manuscript. All authors participated in the interpretation of the data, critical review of subsequent versions of the manuscript as well as contributed significantly to its content. All authors approved the final version of the manuscript.

\section{References}

1. Nielsen J $\varnothing$, Shrestha AD, Neupane D, et al. Non-adherence to anti-hypertensive medication in low- and middle-income countries: a systematic review and meta-analysis of 92443 subjects. J Hum Hypertens. 2017;31(1):14-21. *Gives an insight in medicine adherence in LMICs and explores the factors affecting non-adherence to antihypertensive medicines.

2. WHO. A global brief on hypertension - silent killer, global public health crisis. World Health Day 2013. Available at URL:

http://apps.who.int/iris/bitstream/10665/79059/1/WHO DCO WHD 2013.2 eng.pdf?ua=1. ${ }^{* *}$ Highlight the threat that hypertension poses to increasing mortality in Africa unless addressed

3. World Health Organization. Noncommunicable diseases. Fact sheet. 2017. Available from: http://www.who.int/mediacentre/factsheets/fs355/en/

4. Shen $\mathrm{Y}$, Peng $\mathrm{X}$, Wang $\mathrm{M}$, et al. Family member-based supervision of patients with hypertension: a cluster randomized trial in rural China. J Hum Hypertens. 2016;1-8

5. Irazola VE, Gutierrez L, Bloomfield G, Carrillo-Larco RM, Dorairaj P, Gaziano T, et al. Hypertension Prevalence, Awareness, Treatment, and Control in Selected LMIC Communities: Results From the NHLBI/UHG Network of Centers of Excellence for Chronic Diseases. Global heart. 2016;11(1):47-59

6. Alhalaiqa $\mathrm{F}$, Deane $\mathrm{KHO}$, Nawafleh $\mathrm{AH}$, et al. Adherence therapy for medication non-compliant patients with hypertension: a randomised controlled trial. J Hum Hypertens. 2012;26:117-126.

7. Muhamedhussein MS, Nagri ZI, Manji KP. Prevalence, risk factors, awareness, and treatment and control of hypertension in Mafia Island, Tanzania. Int J Hypertens. 2016. doi:10.1155/2016/1281384.

8. Abegaz TM, Shehab A, Gebreyohannes EA, Bhagavathula AS, Elnour AA. Nonadherence to antihypertensive drugs: A systematic review and meta-analysis. Medicine. 2017;96(4):e5641. ${ }^{* *}$ Indicates that more than three quarters or more of hypertensive patients are currently failing to achieve target blood pressure goals

9. Boima V, Ademola AD, Odusola AO, Agyekum F, Nwafor CE, Cole H, et al. Factors Associated with Medication Nonadherence among Hypertensives in Ghana and Nigeria. International Journal of Hypertension. 2015;2015:205716

10. Adebolu FA, Naidoo M. Blood pressure control amongst patients living with hypertension presenting to an urban district hospital outpatient clinic in Kwazulu-Natal. Afr J Prim Health Care Fam Med. 2014;6(1):6

11. Jolles PE, Padwal RS, Clark AM, et al. A qualitative study of patient perspectives about hypertension. Int Sch Res Notices.2013;ID671691.10.doi:10.5402/2013/671691. Available from: http://www.hindawi.com/ism/hypertension/2013/671691

12. Jande M, Katabalo DM, Sravanam P, Marwa C, Madlan B, Burger J, et al. Patient-related beliefs and adherence toward their medications among the adult hypertensive outpatients in Tanzania. Journal of comparative effectiveness research. 2017

13. Mungal-Singh V. Lifestyle changes for hypertension. S Afr Fam Pract. 2012;54(2): S12-S16. Suppl 1

14. Kamran A, Ahari SS, Biria M, et al. Determinants of Patient's Adherence to Hypertension Medications. Ann Med Health Science Res. 2014;4:922-927

15. Calhoun DA, Jones D, Textor S, Goff DC, Murphy TP, Toto RD, et al. Resistant hypertension: diagnosis, evaluation, and treatment. A scientific statement from the American Heart Association Professional Education Committee of the Council for High Blood Pressure Research. Hypertension. 2008;51(6):1403-19. 
16. Ambaw AD, Alemie GA, W/Yohannes SM, Mengesha ZB. Adherence to antihypertensive treatment and associated factors among patients on follow up at University of Gondar Hospital, Northwest Ethiopia. BMC public health. 2012;12:282

17. Garfield S, Clifford S, Eliasson L, Barber N, Willson A. Suitability of measures of self-reported medication adherence for routine clinical use: A systematic review. BMC Medical Research Methodology. 2011; 11:149.

18. Moosa MS, Kuttschreuter LS, Rayner BL. Evaluation and management of patients referred to a tertiary-level hypertension clinic in Cape Town, South Africa. S Afr Med J. 2016; 106:106

19. Fernandez-Arias M, Acuna-Villaorduna A, Miranda JJ, Diez-Canseco F, Malaga G. Adherence to Pharmacotherapy and Medication-Related Beliefs in Patients with Hypertension in Lima, Peru. PloS one. 2014;9(12):e112875.

20. Gwadry-Sridhar FH, Manias E, Lal L, Salas M, Hughes DA, Ratzki-Leewing A, et al. Impact of interventions on medication adherence and blood pressure control in patients with essential hypertension: a systematic review by the ISPOR medication adherence and persistence special interest group. Value in health. 2013;16(5):863-71

21. Nguyen T, La Caze A, Cottrell $N$. What are validated self-report adherence scales really measuring? Br J Clin Pharmacol. 2014;77:427-445.

22. Hofman K. 2014. Non-communicable disease in South Africa: A challenge to economic development. S Afr Med J. 2014; 104:647

23. Jimmy B, Jose J. Patient Medication Adherence: Measure in Daily Practice. Omen Medical Journal. 2011; 26(3):155-159

24. Mash B, Fairall L, Adejayan O, Ikpefan O, Kumari J, Mathee S, et al. A morbidity survey of South African primary care. PloS one. 2012;7(3):e32358. *Indicates the need to assess medicine use by patients at the PHC facilities in SA because majority of chronic patients are managed at this level.

25. Rampamba EM, Meyer JC, Helberg E, Godman B. Knowledge of hypertension and its management among hypertensive patients on chronic medicines at primary health care public sector facilities in South Africa; findings and implications. Expert review of cardiovascular therapy. 2017;15(8):639-647. *Highlights the increase in hypertension prevalence, with over $50 \%$ of the adult population pontetialy having hypertension and relying on PHC services in South Africa.

26. Meyer JC, Schellack N, Stokes J, et al. Ongoing Initiatives to Improve the Quality and Efficiency of Medicine Use within the Public Healthcare System in South Africa; A Preliminary Study. Frontiers in pharmacology. 2017;8(751).**Discusses ongoing initiatives in improving medicines availability and care for patiets with chronic diseases in South Africa.

27. Cois A, Day C. Obesity trends and risk factors in the South African adult population. BMC obesity. 2015;2:42.

28. Statistics South Africa. Mortality and causes of death in South Africa, 2016: Findings from death notification. Available at URL: http://www.statssa.gov.za/publications/P03093/P030932016.pdf

29. McHiza ZJ, Parker W-a, Makoae M, Sewpaul R, Kupamupindi T, Labadarios D. Body image and weight control in South Africans 15 years or older: SANHANES-1. BMC public health. 2015;15:992.

30. Nashilongo MM, Singu B, Kalemeera F, et al. Assessing Adherence to Antihypertensive Therapy in Primary Health Care in Namibia: Findings and Implications. Cardiovascular drugs and therapy. 2017;31(5-6):565-578

31. Okwuonu CG, Ojimadu NE, Okaka El, et al. Patient-related barriers to hypertension control in a Nigerian population. Int J Gen Med. 2014;7:345-353

32. Ofili MI, Ncama BP, Sartorius B. Hypertension in rural communities in Delta State, Nigeria: Prevalence, risk factors and barriers to health care. African Journal of Primary Health Care \& Family Medicine. 2015;49(1):875

33. Rigby D. Collaboration between doctors and pharmacists in the community. Aust Prescriber. 2010;33(6):191-193.

34. National Department of Health (NDoH). 2014. Standard treatment guidelines and essential medicines list for South Africa. Pretoria: $\mathrm{NDoH} ; 2014$. Available from: http://www.kznhealth.gov.za/pharmacy/edlphc2014a.pdf.

35. Dawes MG, Kaczorowski J, Swanson G, Hickey J, Karwalajtys T. 2010. The effect of a patient education booklet and BP tracker on knowledge about hypertension: A randomized controlled trial. Family Practice. 2010; 27:472-478. ${ }^{* *}$ Support the needs for studies evaluating the role of information on patient medication-taking behavior as well as factors hindering adherence

36. Nguyen T, Schuiling-Veninga CCM, Nguyen TY, Vu T, Wright EP, Postma1 MJ. Adherence to hypertension medication: Quantitative and qualitative investigations in a rural Northern Vietnamese community. Plos One. 2017; 12(2):e0171203. 
37. Khothatso T, Moshoeshoe T, Saroni Z, et al. Knowledge of hypertensive patients about treatment in the Seboche hospital. S Afri Fam Pract. 2013;58:S27-S28

38. Jacobs K, Julyan M, Lubbe MS, et al. Medicine possession ratio as proxy for adherence to antiepileptic drugs: prevalence, associations, and cost implications. Patient Prefer Adherence. 2016; 10:539-547

39. Health System Trust (HST). 2015. Central chronic medicines dispensing and distribution programme (CCMDD). Available from: http://www.hst.org.za/projects/central-chronic-medicinedispensing-and-distribution-programme-ccmdd

40. Republic of South Africa for South Africa. Towards universal health coverage. 2015. Available from:

http://www.gov.za/sites/www.gov.za/files/National_Health_Insurance_White_Paper_10Dec2015.p df.

41. MEDIA RELEASE. GAUTENG DEPARTMENT OF HEALTH / RIGHT TO CARE / RIGHT EPHARMACY. Medication ATMs launched in SA: patient waiting times cut to under 3 minutes. 15 March 2018. Available at URL: http://rightepharmacy.co.za/medication-atms-launched-in-sa-patient-waitingtimes-cut-to-under-3-minutes/

42. IT News Africa. South Africa gets first-of-its kind ATM pharmacy. 16 March 2018. Available at URL: http://www.itnewsafrica.com/2018/03/south-africa-gets-first-of-its-kind-atm-pharmacy/

43. Patel S, Dowse R. Understanding the medicines information-seeking behaviour and information needs of South African long-term patients with limited literacy skills. Health Expect. 2015 Oct; ;18(5):1494-14507.

44. Jimmy B, Jose J. Patient medication adherence: Measures in daily practice. Oman Med J. 2011;26(3): 155-159

45. Wilson I, Fowler J, Cosenza C, et al. Lessons from cognitive testing of self-report adherence items. 2012. Available from: http://www.iapac.org/AdherenceConference/presentations/ADH7 79952.pdf. **Indicates the importance of assessing adherence to medication using patient self-report questionnaire that measure adherence in the past 30 days using words to measure adherence instead of numbers.

46. Elsous E, Radwan M, Al-Sharif H, Mustafa AA, Medications Adherence and Associated Factors among Patients with Type 2 Diabetes Mellitus in the Gaza Strip, Palestine. Front Endocronol. 2017;8:100. doi: 10.3389/fendo.2017.00100

47. Vagiri RV, Meyer JC, Gous AGS. Health-related quality of life and adherence to antiretroviral treatment over a 12-month period for patients attending two public sector clinics in South Africa. Afr J Phy Health Educ Recreat Dance. 2015;21:228-240.

48. Lu M, Safren SA, Skonlnik PR, et al. Optimal recall period and response task for self-reported HIV medication adherence. AIDS Behaviour. 2008; 12(1):86-94.

49. Khayyat SM, Khayyat SMS, Alhazmi RSH, et al. Predictors of medication adherence and blood pressure control among Saudi hypertensive patients attending primary care clinics: A Crosssectional study. PLoS ONE. 2017. 12(1): e0171255

50. Iloh GUP, Ofoedu JN, Njoku PU, Amadi AN, Godshwill-Uko EU. Medication adherence and blood pressure control amongst adults with primary hypertension attending a tertiary hospital primary care clinic in Eastern Nigeria. Afr J Prm Health Care Farm Med. 2013;5(1), Art. \#446, 6 pages. http://dx.doi.org/10.4102/phcfm.v5i1.446

51. Osamor PE, Owumi BE. Factors associated with treatment compliance in hypertension in Southwest Nigeria. J Health Popul Nutr. 2011; 29:619-628.

52. Kang CD, Tsang PP, Wang HH, et al. Determinants of medication adherence and blood pressure control among hypertensive patients in Hong Kong: a cross-sectional study. Int J Cardiol. 2015; $1: 250-7$

53. Tugli AK, Ramaano NS, Klu EK, et al. Assessing medication default, alcohol intake and smoking habits among hypertensive patients in a rural village of Limpopo Province, South Africa. MJSS. 2014; 5(23): 1614-20

54. Chen S, Lee W, Liang $\mathrm{T}$, et al. Factors associated with gender differences in medication adherence: a longitudinal study. J Adv Nurs. 2014; 70:2031-2040.

55. Ramaano NS, Tugli AK, Akinsola HA, Ramathuba D. Socio-economic characteristics and predisposing factors contributing to high blood pressure among hypertensive patients at Folovhodwe village, Limpopo Province, South Africa. Afr J Phy Health Educ Recreat Dance. 2014; 20(4:1):1342-1352.

56. Shirindi ML, Makhubele JC, Fraeyman J. Barriers to medication adherence among women living in rural areas suffering from hypertension. Ethn Med J. 2016; 10:76-84. 
57. Osamor PE. Social support and management of hypertension in south-west Nigeria. Cardiovasc $J$ Afr. 2015; 26:29-33.

58. Olowookere AJ, Olowookere SA, Talabi AO, et al. Perceived family support and factors influencing medication adherence among hypertensive patients attending a Nigerian tertiary hospital. Ann Trop Med Public Health. 2015; 8:241-245.

59. Albrecht, S. The Pharmacist's role in medication adherence. US Pharmacist. 2011; 36:45-48.

60. Viera AJ, Cohen LW, Mittchell CM, et al. High blood pressure knowledge among primary care patients with known hypertension. J Am Board Fam Med. 2008;21: 300-308.

61. Taba P, Rosenthal M, Habicht J, Tarien H, Mathiesen M, Hill S, et al. Barriers and facilitators to the implementation of clinical practice guidelines: A cross-sectional survey among physicians in Estonia. BMC health services research. 2012;12:455

62. Fitzgerald A, Lethaby A, Cikalo M, Glanville J, Wood H. Review of Systematic Reviews Exploring the Implementation/Uptake of Guidelines. York Health Economics Consortium. Available at URL: https://www.nice.org.uk/guidance/ph56/evidence/evidence-review-2-431762366

63. Donnellan C, Sweetman S, Shelley E. Health professionals' adherence to stroke clinical guidelines: a review of the literature. Health policy. 2013;111(3):245-63.

64. Mbui JM, Oluka MN, Guantai EM, et al. Prescription patterns and adequacy of blood pressure control among adult hypertensive patients in Kenya; findings and implications. Expert review of clinical pharmacology. 2017;10(11):1263-1271

65. Gillespie U, Dolovich L, Dahrouge S. Activities performed by pharmacists integrated in family health teams: Results from a web-based survey. Canadian Pharmacists Journal. 2017;150(6):407-416. 